Supporting Information

\title{
Ultrafast and Efficient Transport of Hot Plasmonic Electrons by Graphene for Pt Free, Highly Efficient Visible-Light Responsive Photocatalyst
}

Dinesh Kumar, ${ }^{\dagger}$ Ahreum Lee, ${ }^{\dagger}$ Taegon Lee, ${ }^{\star}$ Manho Lim ${ }^{\ddagger}$ and Dong-Kwon Lim ${ }^{*}, \dagger$

${ }^{\dagger}$ KU-KIST Graduate School of Converging Science and Technology, Korea University, 145 Anam-ro, Seongbuk-gu, Seoul 136-701, South Korea.

Department of Chemistry and Chemistry Institute for Functional Materials, Pusan National University, Busan, 609-735 South Korea.

Corresponding Author (E-mail: dklim@korea.ac.kr)

This PDF include experimental details, figures (S1-S4), and references. 


\section{General}

All chemical reagents were purchased from Sigma-Aldrich (St. Louis, MO, USA) and used as received without further purification. C-flat ${ }^{\mathrm{TM}}$ carbon grids (Electron Microscopy Sciences, Hatfield, PA, USA) and HR-TEM (JEOL-2010, Japan, $200 \mathrm{kV}$ ) were used for TEM analysis. Extinction spectra were obtained with a UV spectrometer (SCINCO, South Korea). Structural analyses were performed using X-ray diffraction (Rigaku D/MAX 2500Tokyo, Japan). The amount of $\mathrm{CO}_{2}$ dissolved in the reaction samples was determined using an HI 3818 carbon dioxide test kit (Hanna Instruments, Romania). ${ }^{1} \mathrm{H}-\mathrm{NMR}$ and ${ }^{13} \mathrm{C}-\mathrm{NMR}$ analyses were carried out using a JEOL JNM AL-400 instrument. The GC-MS analysis was carried out with an Agilent 7890A gas chromatogram. Fourier transform infrared (FT-IR) spectra were recorded on a Jasco FTIR-4200 spectrophotometer (Maryland, USA). An Andor Shamrock SR-303i-A spectrophotometer was used for the Raman analysis. A Xe lamp (Ceramaxs, Waltham, USA) with an output power of 5.41 W was used as a visible light (400-780 nm) source. In addition, a near-infrared (NIR) laser (Sanctity ${ }^{\circledR}$ Laser SSL-808-6000-10TM-MF, Shanghai, China; 808 nm, output power was $4.99 \mathrm{~W}$ ) was used. A solar simulator (Thermo Oriel ${ }^{\circledR}$ Solar Simulator, 911601000 , USA) with a power density of $0.15 \mathrm{~W} / \mathrm{cm}^{2}$ was used.

\section{Method}

\section{II-1. Preparation of nanosized graphene oxide (GO)}

Graphene oxide (GO) was prepared by a modified version of Hummer's method. ${ }^{1}$ A 9:1 mixture of concentrated $\mathrm{H}_{2} \mathrm{SO}_{4} / \mathrm{H}_{3} \mathrm{PO}_{4}(360: 40 \mathrm{~mL})$ was added to a mixture of graphite flakes $(3.0 \mathrm{~g})$. With stirring and cooling in an ice bath, $\mathrm{KMnO}_{4}(18.0 \mathrm{~g})$ was slowly added to the reaction mixture, producing a slight exotherm of $35-40{ }^{\circ} \mathrm{C}$. The reaction was then heated to between 50 and $55^{\circ} \mathrm{C}$ and stirred for $12 \mathrm{~h}$. The reaction mixture was cooled to room temperature and then poured into iced-water $(400 \mathrm{~mL})$ containing $30 \% \mathrm{H}_{2} \mathrm{O}_{2}(3.0 \mathrm{~mL})$. The solution was then filtered through a metal US Standard testing sieve (W.S. Tyler, $300 \mu \mathrm{m}$ ). The filtrate was centrifuged $(8,000 \mathrm{rpm}$ for $30 \mathrm{~min})$ and the supernatant was decanted. The remaining gel-like product was then washed in succession with water $(200 \mathrm{~mL}), \mathrm{HCl}(30 \%, 200 \mathrm{~mL})$, ethanol (200 $\mathrm{mL}$ ), and then water again until the solution $\mathrm{pH}$ was 5.0-6.0. The resulting suspension was filtered through a PTFE membrane with a pore size of $0.45 \mu \mathrm{m}$ and then lyophilized to produce a 
fluffy GO powder. GO powder $(5.0 \mathrm{mg})$ was dissolved in triple-distilled water (>18 $\mathrm{M} \Omega, 10 \mathrm{~mL})$ and exfoliated by prolonged sonication (35\% amplitude, $500 \mathrm{~W}, 2.0 \mathrm{~h}$ ). The solution was centrifuged several times until no precipitate was observed (15,000 rcf, $20 \mathrm{~min}$ ).

\section{II-2. Preparation of positively charged AuNPs}

To a mixture composed of $\mathrm{HAuCl}_{4}(40 \mathrm{~mL}, 1.42 \mathrm{mM})$ and cysteamine aqueous solution $(400 \mu \mathrm{L}, 213 \mu \mathrm{M})$, fresh sodium borohyride $\left(10 \mu \mathrm{L}, 10 \mathrm{mM}, \mathrm{NaBH}_{4}\right)$ was added with gentle stirring; then, the mixture was stirred for $12 \mathrm{~h}$ at room temperature. ${ }^{2}$ The purple solution was centrifuged twice at 2,000 rcf for 15 min to obtain the purified AuNP solution (30 nm). TEM, DLS, and UV-visible spectra were used to evaluate the average particle size, shape and optical properties.

\section{II-3. Preparation of CTAB-modified AuNRs (Aspect ratio; 3.5)}

The cetyltrimethyl ammonium bromide (CTAB)-mediated growth method was used to synthesize gold nanorods (AuNRs). ${ }^{3}$ To make a seed solution, $\mathrm{HAuCl}_{4}(0.25 \mathrm{~mL}, 0.01 \mathrm{M})$ was mixed with a CTAB aqueous solution $(9.75 \mathrm{~mL}, 0.1 \mathrm{M})$. Ice-cold $\mathrm{NaBH}_{4}(0.6 \mathrm{~mL}, 0.01 \mathrm{M})$ was quickly added with vigorous stirring, and the solution color changed from yellow to pale-brown. This solution was stored in a water bath to age for $3 \mathrm{~h}$ at $28{ }^{\circ} \mathrm{C}$. To make a growth solution, CTAB $(475 \mathrm{~mL}, 0.1 \mathrm{M})$ was combined with the following solutions with slow stirring in the following order: $\mathrm{HAuCl}_{4}(20 \mathrm{~mL}, 0.01 \mathrm{M}), \mathrm{AgNO}_{3}(3.0 \mathrm{~mL}, 0.01 \mathrm{M})$, and ascorbic acid $(3.2 \mathrm{~mL}$, $0.1 \mathrm{M})$. On adding ascorbic acid, the yellow solution became colorless. Finally, the seed solution $(3.60 \mathrm{~mL})$ was quickly added to the growth solution. After briefly shaking the solution by hand for $5 \mathrm{~s}$, the solution was placed in a water bath at $28{ }^{\circ} \mathrm{C}$ for $12 \mathrm{~h}$ without stirring. The CTABAuNR solution was kept in a water bath at $28{ }^{\circ} \mathrm{C}$ before it was used for the next step. Immediately before starting the next step, the excess CTAB in the solution was removed by repeated centrifugation (15,000 rcf for $20 \mathrm{~min})$. Then, the precipitate was dispersed in distilled water. 


\section{II-4. Preparation of GO-coated or r-GO-coated gold nanoparticles}

The synthesis of GO-coated or r-GO-coated gold nanoparticles was performed by previously reported methods. ${ }^{2}$ The electrostatic interactions between positively charged AuNPs and negatively charged GO were used to produce GO-coated AuNPs. First, the AuNP solution (10 mL; optical density (OD) 1.0 at $540 \mathrm{~nm}$ ) was dropped into a solution of nano-sized GO solution $(10 \mathrm{~mL}, 0.05 \mathrm{mg} / \mathrm{mL})$ with gentle stirring at room temperature. The mixture was then incubated for $12 \mathrm{~h}$ at room temperature. The mixture was centrifuged twice at 15,000 rcf for 15 min to remove excess GO from the precipitate. The precipitate was then dispersed in distilled water $(10 \mathrm{~mL})$ (It should be noted that the nano-sized GO was not centrifuged down at such condition (15,000 rcf, $15 \mathrm{~min})$ because of their small size). Then, GO-AuNP solution (10 $\mathrm{mL})$ was reacted at $95-100{ }^{\circ} \mathrm{C}$ in the presence of ammonia solution $(250 \mu \mathrm{L}, 28 \%)$ and hydrazine monohydrate $\left(50 \mu \mathrm{L}, \mathrm{NH}_{2} \mathrm{NH}_{2}-\mathrm{H}_{2} \mathrm{O}\right){ }^{3}$ The solution color changed from pale yellow brown to dark brown as the reaction progressed (as GO was converted into r-GO). After completion of the reaction, the particle solutions were centrifuged twice at 15,000 $\mathrm{rcf}$ for $15 \mathrm{~min}$ to remove the reagents (hydrazine and ammonia) and then dispersed in distilled water. The same method was used to prepare the r-GO coated AuNRs.

\section{II-5. $\mathrm{CO}_{2}$ reduction under $\mathrm{H}_{2}$ gas flow}

$\mathrm{CO}_{2}$ reduction was carried out in the presence of a continuous flow of $\mathrm{H}_{2}$ for $3 \mathrm{~h}$ without light irradiation. $\mathrm{H}_{2}$ gas was generated by adding an aluminum foil to $\mathrm{NaOH}$ solution $(200 \mathrm{~mL}$, $2.0 \mathrm{M}){ }^{4}$ The as-generated $\mathrm{H}_{2}$ gas was passed into $\mathrm{CO}_{2}$-saturated distilled water continuously for $3 \mathrm{~h}$. Then, after adjusting the $\mathrm{pH}$ to 12.0 with dilute $\mathrm{NaOH}$, the solution was evaporated to dryness. The product was analyzed by ${ }^{1} \mathrm{H}-\mathrm{NMR}$ and ${ }^{13} \mathrm{C}-\mathrm{NMR}$.

\section{II-6. Chemical yield calculation}

(1) The amount of $\mathrm{CO}_{2}$ in $10 \mathrm{~mL}$ solution was $2.4 \mathrm{mg}$, as quantified by using a "carbon dioxide kit" (HI 3818, Hanna Instruments, Romania). The flask was rinsed with a $\mathrm{CO}_{2}$-purged aqueous sample $(5 \mathrm{~mL})$ containing 1 drop of phenolphthalein indicator: there was no change in the color of the indicator solution. Subsequently, the mixture was titrated with the HI 3818-0 solution 
provided by the " $\mathrm{CO}_{2}$ kit" until the solution color turned pink. The amount of the titration solution consumed (in $\mathrm{mL}$ ) was multiplied by 100 to obtain the quantity $\left(\mathrm{mg} / \mathrm{L}(\mathrm{ppm})\right.$ ) of $\mathrm{CO}_{2}$. The experiment was repeated for three times.

(2) The quantification of formic acid was carried out using a standard deviation curve plotted using ${ }^{1} \mathrm{H}-\mathrm{NMR}$ and GC-mass analysis from five standard samples of formic acid in $\mathrm{D}_{2} \mathrm{O}$. The five samples had increasing concentrations, ranging from $0.015 \mathrm{mM}$ to $0.15 \mathrm{mM}$.

For NMR analysis, the reaction sample after the completion of $\mathrm{CO}_{2}$ reduction was collected and then made alkaline with aqueous $\mathrm{NaOH}$ until $\mathrm{pH}$ 12.0. This converted the formic acid $(\mathrm{HCOOH})$ to sodium formate $\left(\mathrm{HCOO}^{-} \mathrm{Na}^{+}\right)$. After evaporation of water by rotary evaporation, the resulting sample was dissolved in $\mathrm{D}_{2} \mathrm{O}$ and analyzed by ${ }^{1} \mathrm{H}-\mathrm{NMR}(400 \mathrm{MHz})$ and ${ }^{13} \mathrm{C}-\mathrm{NMR}(400 \mathrm{MHz})$.

For $\mathrm{GC}$ analysis, the oven temperature was varied from $35{ }^{\circ} \mathrm{C}$ to $100{ }^{\circ} \mathrm{C}$ using helium gas as the carrier gas with an injector temperature of $200{ }^{\circ} \mathrm{C}$ and a sampling time of $20 \mathrm{~min}$ for GC-MS analysis. The equation obtained from the standard deviation curve was used to calculate the number of moles of formic acid formed.

(3) The chemical yield was calculated by dividing the molar concentration of formic acid formed by the molar concentration of carbon dioxide dissolved in the reaction sample. For example:

The equation obtained from standard deviation curve (NMR):

Moles of $\mathrm{HCOOH} \div 10 \mathrm{~mL}=0.00014184 \mathrm{M}$ (from standard deviation curve)

Moles of $\mathrm{CO}_{2} \div 10 \mathrm{~mL}=0.005455 \mathrm{M}$ (calculated using the carbon dioxide kit)

Chemical yield $=$ moles of $\mathrm{HCOOH} \div$ Moles of $\mathrm{CO}_{2} \times 100$

$$
=0.00014184 \div 0.005455 \times 100=2.6 \%
$$




\section{II-7. Quantum yield calculation}

The quantum yield of produced formic acid was calculated by using following equation:

QY $(\%)=$ number of reacted electrons $\div$ number of incident photons $\times 100 \%$

$=2 \times$ number of formic acid molecules/ number of incident photons $\times 100 \%$

Number of incident photons $=$ moles of $\mathrm{Fe}^{2+} \div \phi_{\lambda} \times \mathrm{t} \times \mathrm{F}$

$\left(\right.$ Moles of $\mathrm{Fe}^{2+}($ calculated $)=0.03588, \phi_{\lambda}=$ quantum yield of $\mathrm{Fe}^{2+}$ ion concentration $=0.65, \mathrm{t}=$ time $=20 \mathrm{~s}$,

$\mathrm{F}=$ mean fraction of light absorbed by ferrioxalate solution $=0.1488$

Number of incident photons $=0.03588 \div 0.65 \times 20 \times 0.1488$

$$
=0.01855 \text { photons } \mathrm{s}^{-1}
$$

QY $(\%)=2 \times$ number of formic acid molecules/number of incident photons $\times 100 \%$

$$
=2 \times 0.00014184 / 0.01855 \times 100=1.52 \%
$$

The number of incident photons was measured by the ferrioxalate actinometer method (equations (5) and (6)). ${ }^{5,6}$ The actinometer solution was prepared as follows. In a 100-mL flask, an aqueous solution of $\mathrm{Fe}_{2}\left(\mathrm{SO}_{4}\right)_{3}(5 \mathrm{~mL}, 0.2 \mathrm{M})$ and an aqueous solution of $\mathrm{K}_{2} \mathrm{C}_{2} \mathrm{O}_{4}(5 \mathrm{~mL} 1.2 \mathrm{M})$ were added. Then, this mixture was diluted to $100 \mathrm{~mL}$ volume by using distilled water. Then, the above actinometer solution (40 mL) was irradiated under visible light for $20 \mathrm{~s}$.

Consequently, the ferrous ion concentration was determined by the formation of the ironphenanthroline complex, detected by UV-visible spectrophotometry at $510 \mathrm{~nm}$. The analytical procedure was as follows. In a 100-mL flask, the actinometer solution (1 mL) after irradiation, an aqueous solution of 1,10-phenanthroline ( $2 \mathrm{~mL}, 0.2 \mathrm{wt} \%)$, and a buffer solution $(0.5 \mathrm{~mL}) \mathrm{of} \mathrm{pH}$ = 4-5 were mixed and diluted to $100 \mathrm{~mL}$ with distilled water, and kept in the dark for $30 \mathrm{~min}$. After $30 \mathrm{~min}$, absorbance of the solution at $510 \mathrm{~nm}$ was measured using a UV-visible spectrophotometer. A comparative test was conducted by following the abovementioned procedure for the blank solution (actinometer solution without irradiation), and the ferrous ion concentration was calculated by UV-visible spectrophotometric observation at $510 \mathrm{~nm}$. 


\section{II-8. Femtosecond transient absorption spectroscopic analysis}

For sample preparation, the amount of gold nanoparticles was carefully controlled based on the OD value at $530 \mathrm{~nm}$ and mixed it with accurately weighed $\mathrm{TiO}_{2}$ nanoparticle powder (i.e., $100 \mu \mathrm{L}$ of nanoparticle solution (OD 10.0) was mixed $1.0 \mathrm{mg}$ of $\mathrm{TiO}_{2}$ nanoparticle powder (20 $\mathrm{nm})$ ). The $10 \mu \mathrm{L}$ of nanoparticle- $\mathrm{TiO}_{2}$ mixture solution was spotted on the $\mathrm{KBr}$ pellets, then it was dried and measured three times for each sample. The instrumental setup of femtosecond vibrational spectrometer is described in the previous report. ${ }^{7}$ Briefly, two optical parametric amplifier is pumped by $800 \mathrm{~nm}$ pulse which pumped by Ti:S oscillator/amplifier system at a repetition rate of $1 \mathrm{kHz}$ to generate signal and idler. One signal/idler pair passed $\mathrm{AgGaS}_{2}$ crystal to make mid-IR $\left(2730-3130 \mathrm{~cm}^{-1}\right)$. The other signal is frequency doubled by BBO cryatal to generate visible light $(575 \mathrm{~nm})$. Visible pulse $(2 \mu \mathrm{J})$ to prevent multi-photon absorption is used as pump pulse to excite AuNPs and mid-IR probes their states. To obtain isotropic absorption, the polarization of pump pulse is rotated $54.7^{\circ}$ to the probe pulse. Broad probe pulse is dispersed with 320-mm IR monochromator with a $1501 / \mathrm{mm}$ grating and it's spectral resolution is $3.3 \mathrm{~cm}^{-}$ $1 /$ pixel at $2930 \mathrm{~cm}^{-1}$. Half of pump pulse is blocked to obtain transient absorption signal $(\mathrm{DA}=$ pumped signal - unpumped signal). Instrument response function was about $220 \mathrm{fs}$. 

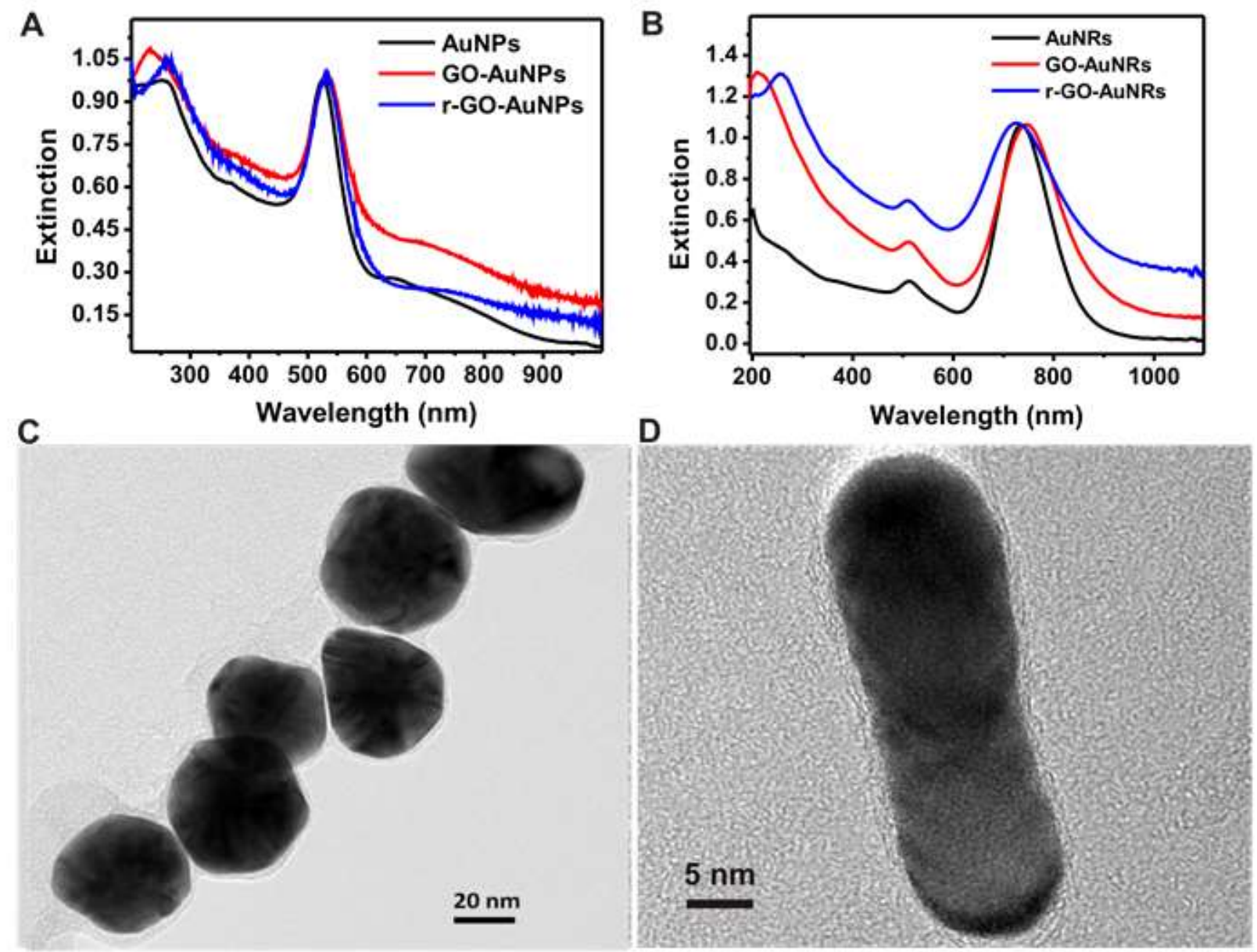

Figure S1. (A) UV-vis spectrum of AuNPs, GO-AuNPs and r-GO-AuNPs. (B) UV-vis spectrum of AuNRs, GO-AuNRs, and r-GO-AuNRs. (C) HR-TEM image of r-GO-AuNPs. (D) HR-TEM image of r-GO-AuNRs. 

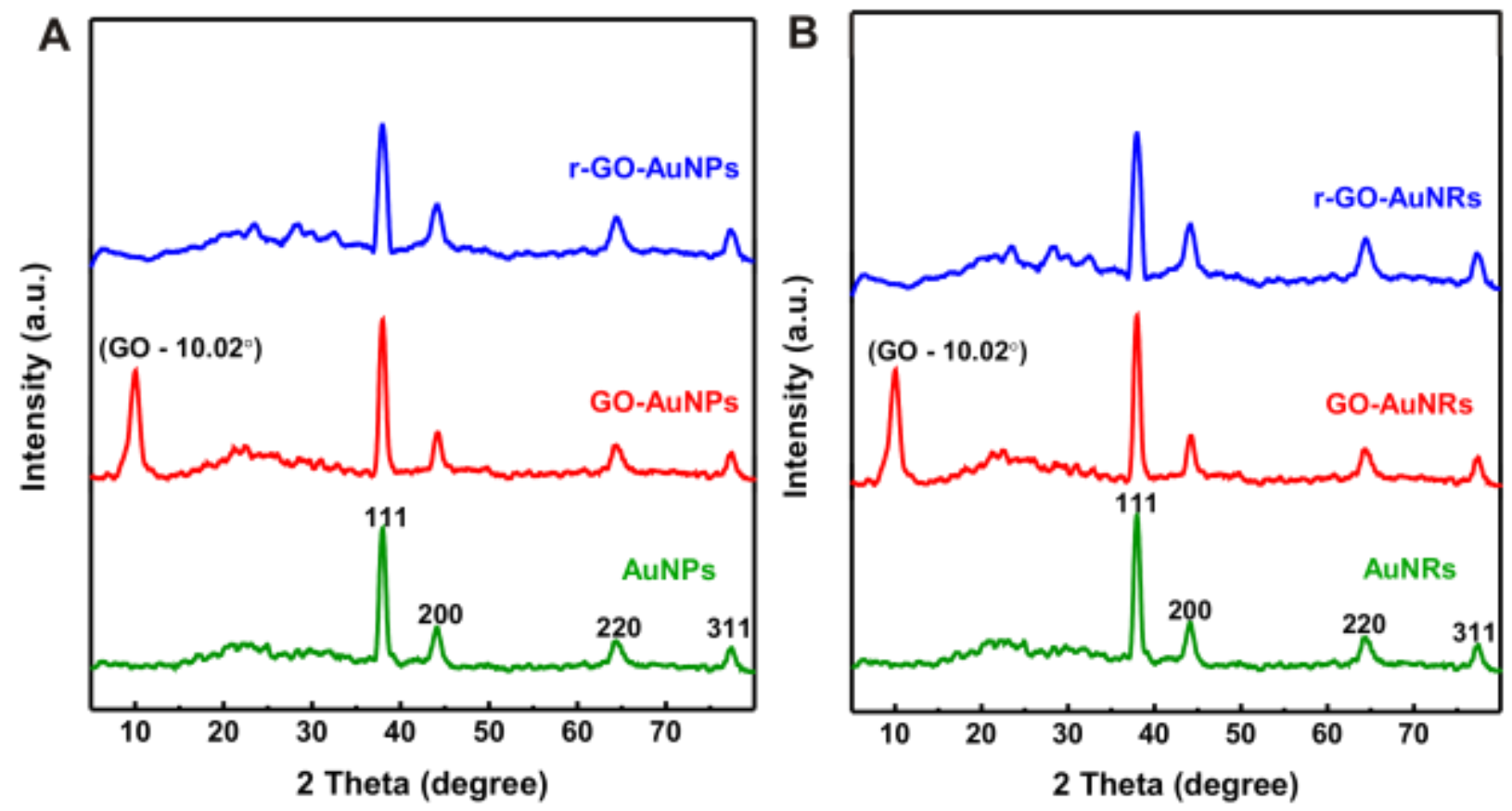

Figure S2. XRD spectrum of (A) AuNPs, GO-AuNPs, and r-GO-AuNPs. (B) AuNRs, GOAuNRs, and r-GO-AuNRs. 

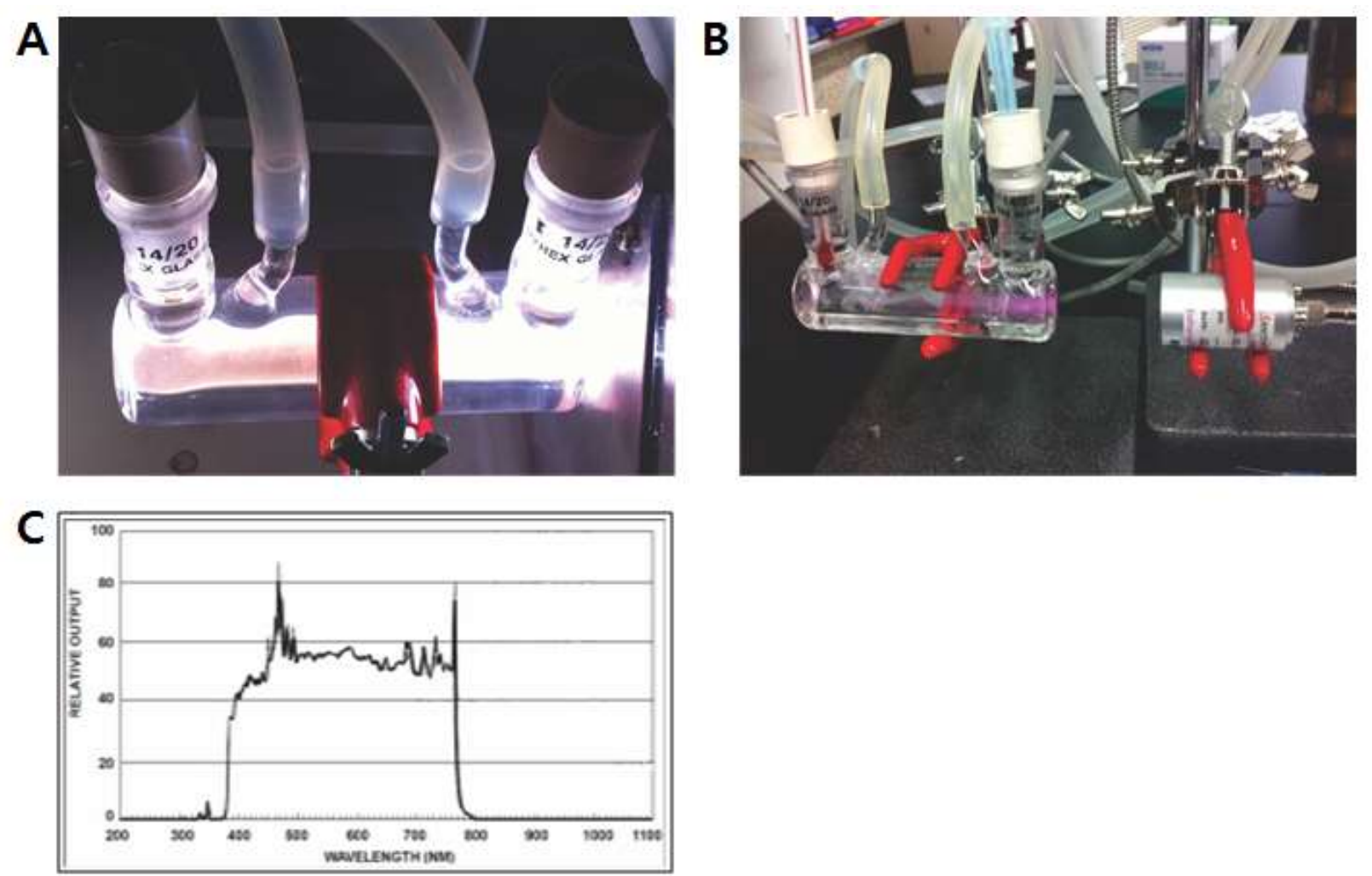

Figure S3. Instrumental setup for $\mathrm{CO}_{2}$ photoconversion. (A) Light from the Xe lamp (400 - 700 $\mathrm{nm}$ ) illuminates the reactor (Pyrex, $10 \mathrm{ml}$ ) with water circulation jacket. (B) Light from the NIR laser $\left(808 \mathrm{~nm}\right.$ ) illuminates the reactor. (C) Output spectra of Xe lamp (Cermax ${ }^{\circledR}$, PE300BFA). 

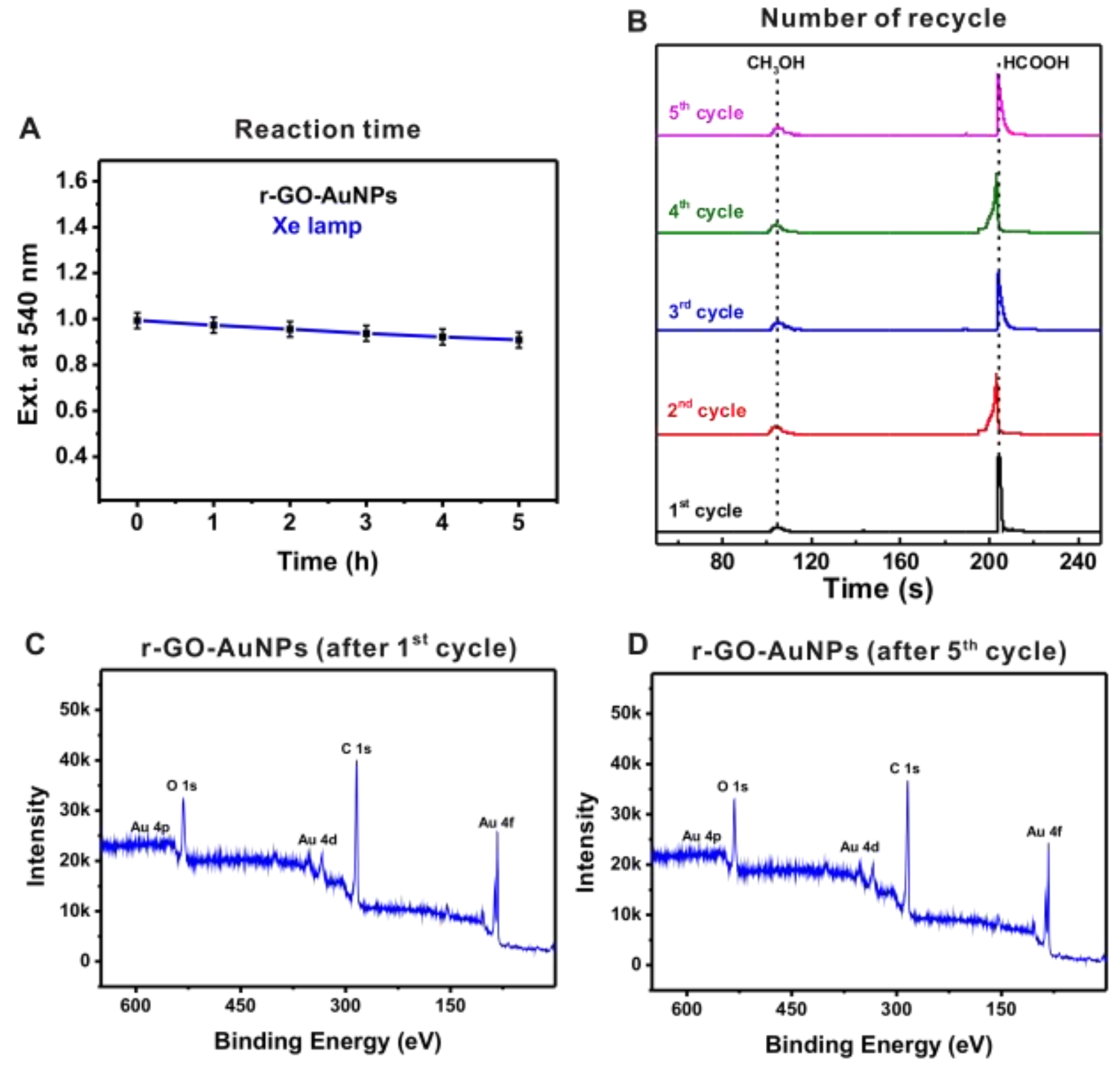

Figure S4. Time-dependent stability of (A) r-GO-AuNPs with visible light irradiation for $5 \mathrm{~h}$. (B) Gas chromatogram of reaction solution after $3.0 \mathrm{~h}$ of illumination with a Xe lamp and recycled r-GO-AuNPs (1-5th cycles). (C, D) Comparative XPS spectrum of r-GO-AuNPs used once and five times. 


\section{References}

1. Marcano, D. C.; Kosynkin, D. V.; Berlin, J. M.; Sinitskii, A.; Sun, Z.; Slesarev, A.; Alemany, L. B.; Lu, W.; Tour, J. M. ACS Nano 2010, 4, 4806-4814.

2. Lim, D.-K.; Barhoumi, A.; Wylie, R. G.; Reznor, G.; Langer, R. S.; Kohane, D. S. Nano Lett. 2013, 13, 4075-4079.

3. Dreyer, D. R.; Park, S.; Bielawski, C. W.; Ruoff, R. S. Chem. Soc. Rev. 2010, 39, 228240.

4. Soler, L.; Macanás, J.; Muñoz, M.; Casado, J. J. Power Sources 2007, 169, 144-149.

5. Schiavello, M.; Augugliaro, V.; Loddo, V.; López-Muňoz, M. J.; Palmisano, L. Res. Chem. Interned. 1999, 25, 213-227.

6. An, C.; Wang, J.; Jiang, W.; Zhang, M.; Ming X.; Wang, S.; Zhang Q. Nanoscale 2012, 4, $5646-5650$.

7. Kim, S.; Jin, G.; Lim, M. J. Phys. Chem. B 2004, 108, 20366-20375. 